\title{
Oral anticoagulation in octogenarians with atrial fibrillation
}

\author{
González Saldivar Hugo ${ }^{\mathrm{a}}$, Lourdes M. Figueiras-Graillet ${ }^{\mathrm{b}}$, Manuel Anguita ${ }^{\mathrm{c}}$, Francisco \\ Marín $^{\mathrm{d}}$, Vicente Bertomeu ${ }^{\mathrm{e}}$, Inmaculada Roldán ${ }^{\mathrm{f}}$, Martín Ruiz ${ }^{\mathrm{c}}$, Javier Muñiz ${ }^{\mathrm{g}}$, Manuel \\ Martínez-Sellés ${ }^{\mathrm{a}, \mathrm{h}, \mathrm{i}}$ on behalf of the FANTASIIA registry investigators see Appendix)
}

\author{
${ }^{a}$ Department of Cardiology, Hospital General Universitario Gregorio Marañón, Madrid, Spain \\ ${ }^{b}$ Facultad de Medicina Campus Xalapa. Universidad Veracruzana, Xalapa, Veracruz, Mexico \\ ${ }^{c}$ Department of Cardiology, Hospital Universitario Reina Sofía, Córdoba, Spain \\ ${ }^{d}$ Department of Cardiology, Hospital Universitario Virgen de la Arrixaca, IMIB-Arrixaca, Murcia, Spain \\ ${ }^{e}$ Department of Cardiology, Hospital San Juan de Alicante, Spain \\ ${ }^{f}$ Department of Cardiology, Hospital Universitario La Paz, Madrid, Spain \\ ${ }^{g}$ Instituto Universitario de Ciencias de la Salud e INIBIC, Universidad de A Coruña, Spain \\ ${ }^{h}$ Universidad Complutense, Madrid, Spain \\ ${ }^{i}$ Universidad Europea, Madrid, Spain
}

\begin{abstract}
Background. Vitamin K antagonists (VKAs) are still largely employed, even in nonvalvular atrial fibrillation (AF). Our aim was to study the clinical profile of octogenarians treated with oral anticoagulation and to study the effect of age on the quality of VKAs anticoagulation.

Methods. Data are from a prospective national registry in an adult Spanish population of nonvalvular AF. We included 1637 patients who had been receiving VKAs for at least 6 months before enrolment.

Results. Mean age was $73.8 \pm 9.4$ years. Patients aged $>80$ years $(\mathrm{N}=429)$ had a high risk profile with higher risk of stroke and bleeding than younger patients; $\mathrm{CHA}_{2} \mathrm{DS}_{2}$-VASc (Cardiac failure, Hypertension, Age > 74, Diabetes, Stroke, Vascular disease, Age 65-74 years, and Sex category) $4.5 \pm 1.3$ vs. $3.5 \pm 1.6, \mathrm{p}<0.001$, HAS-BLED (Hypertension, Abnormal renal/liver function, Stroke, Bleeding history or predisposition, Labile international normalized ratio, Elderly (> 64 years), Drugs/alcohol concomitantly) $2.4 \pm 0.9$ vs. $1.9 \pm 1.1, \mathrm{p}<0.001$. Creatinine clearance was lower in octogenarians than in younger patients $(54.3 \pm 16.1 \mathrm{ml} / \mathrm{min}$ vs. $69.5 \pm 23.7 \mathrm{ml} / \mathrm{min}, \mathrm{p}<0.001)$ and severe renal disease with creatinine clearance $<30 \mathrm{ml} / \mathrm{min}$ was more frequent in octogenarians $(5.2 \%$ vs. $2.2 \%$, $\mathrm{p}<0.001)$. In patients treated with VKAs $(\mathrm{N}=1637)$, the international normalized ratio values of the 6 months previous to enrollment were similar in all age quartiles, as was the time in the therapeutic range.

Conclusion. In this large registry octogenarians with nonvalvular AF had high risk of stroke and bleeding and frequent renal disease. VKAs anticoagulation quality was similar in octogenarians and in younger patients.
\end{abstract}

\section{Keywords}

Atrial fibrillation; Time in therapeutic range; Vitamin K antagonists; Age; Octogenarius 


\section{Introduction}

Atrial fibrillation (AF) is the most common sustained arrhythmia occurring in 1-2\% of the general population and is associated with substantial mortality and morbidity, including stroke and other embolic events [1]. In octogenarians, AF is particularly frequent and is responsible of a quarter of cerebrovascular accidents [2]. In patients with non-valvular AF, Direct Oral Anticoagulants (DOACs) have been proven to be more effective and safer than vitamin $\mathrm{K}$ antagonists (VKAs) [3] but VKAs are still largely employed, mainly due to their low price and the recommendation not to use DOACs in patients, mostly elderly, with severe renal disease [4]. The coagulation status with VKAs needs to be monitored carefully with the international normalized ratio (INR), and the time in the therapeutic range (TTR) calculated by the Rosendaal method [5] is the most widely used formula to assess the quality of anticoagulation, using a linear interpolation to assign an INR value to each day between successive observed INRvalues [6]. Poor anticoagulation control is defined as an estimated $<65 \%$ TTR [7].

Although AF prevalence increases with age [1] previous data show a high rate of inappropriate anticoagulation among octogenarians with $\mathrm{AF}$ [8] and [9], however the data reported in the last five years suggest that this might be changing [10] and [11].Our aim was to study the clinical profile of octogenarians who receive oral anticoagulation due to nonvalvular AF and to study the effect of age on the quality of VKAs anticoagulation assessed by TTR.

\section{Methods}

We used data from FANTASIIA (Spanish acronym for Atrial fibrillation: Influence of anticoagulation level and type on stroke and bleeding event incidence) [12], a prospective national registry in an adult population of Spanish patients with nonvalvular AF who had been receiving oral anticoagulant therapy (by design 80\% VKA and 20\% DOACs) for at least 6 months before enrolment. We analyzed a crosssectional baseline data set from the FANTASIIA enrolment visit to study the association of different risk variables and indexes with age and, specifically to compare INR values of the 6 months previous to the study entry and TTR of octogenarians with younger age groups.

Chronic kidney disease was defined as estimated glomerular filtration rate $<60 \mathrm{~mL} / \mathrm{min} / 1.73 \mathrm{~m}^{2}$. The glomerular filtration rate was estimated using the Cockcroft-Gault, Modification of Diet in Renal Disease or Chronic Kidney Disease Epidemiology Collaboration equations.

The FANTASIIA Registry complies with all the principles of the Declaration of Helsinki and the study protocol was approved by the Clinical Research Ethics Committee at Hospital Universitario de Alicante and by all the local ethics committees. All study participants signed the informed consent.

\subsection{Statistical analysis}

Quantitative variables were described using the mean \pm standard deviation. For between-group comparisons, we used the Student $t$ test or ANalysis Of Variance (ANOVA) for continuous variables and the chi-square test for qualitative variables. Statistical analysis was performed with the SPSS 20.0 statistical package (IBM Corp., Armonk, NY, USA).

\section{Results}

We enrolled 2178 patients. For the present analysis we selected 1637 patients $(75.2 \%)$ treated with VKAs. Mean age was $73.8 \pm 9.4$ years, $56.2 \%$ were men. The comparison of baseline characteristics of the last age quartile (> 80 years) with the first three quartiles is shown in Table 1. Octogenarians had a high risk profile with higher risk of stroke (CHADS2 [Congestive heart failure, Hypertension, Age, Diabetes, Stroke/Transient Ischemic Attack] and $\mathrm{CHA}_{2} \mathrm{DS}_{2}$-VASc [Cardiac failure, Hypertension, Age > 74, Diabetes, Stroke, Vascular disease, Age 65-74 years, and Sex category]) and bleeding (HASBLED [Hypertension, Abnormal renal/liver function, Stroke, Bleeding history or predisposition, Labile international normalized ratio, Elderly (> 64 years) Drugs/alcohol concomitantly]). Moreover renal disease was more frequent and more severe in octogenarians than in younger patients (Fig. 1). In fact, severe renal disease with creatinine clearance $<30 \mathrm{ml} / \mathrm{min}$ affected only $1.5 \%$ of the patients in the first quartile (37-67 years) but was found in 5.2\% of the patients in the last quartile. The main treatment strategy in octogenarians was rate control, while rhythm control was more frequent in the first three age 
quartiles. Finally, patients aged $>80$ year also had paroxysmal atrial fibrillation less frequently. In spite of this different profile, in patients treated with VKAs $(\mathrm{N}=1637)$, the INR values of the 6 months previous to enrolment were similar in all age quartiles, as was the TTR (Table 2).

Table 1. Comparison of baseline characteristics between the first three quartiles and the last age quartile (> 80 years).

\begin{tabular}{|c|c|c|c|c|}
\hline & $\begin{array}{c}\text { All } \\
\mathrm{N}=1637\end{array}$ & $\begin{array}{c}\text { Q1-Q3 (37-80 years) } \\
\mathrm{N}=1208\end{array}$ & $\begin{array}{c}\text { Q4 (> } 80 \text { years) } \\
\mathrm{N}=429\end{array}$ & $\mathrm{p}$ \\
\hline Women $(\%)$ & $717(43.8)$ & $473(39.2)$ & $244(56.9)$ & $<0.001$ \\
\hline Hypertension (\%) & $1322(80.8)$ & $966(80.0)$ & $356(83.0)$ & 0.18 \\
\hline Hyperlipidemia (\%) & $868(53.0)$ & $661(54.7)$ & $207(48.3)$ & 0.02 \\
\hline Diabetes (\%) & $499(30.5)$ & $384(31.8)$ & $115(26.8)$ & 0.04 \\
\hline Tobacco consumption (\%) & $84(5.1)$ & $80(6.6)$ & $4(1.0)$ & $<0.001$ \\
\hline COPD $(\%)$ & $290(17.7)$ & $216(17.9)$ & $74(17.3)$ & 0.78 \\
\hline Previous bleeding (\%) & $51(3.1)$ & $34(2.8)$ & $17(3.9)$ & 0.34 \\
\hline Heart failure $(\%)$ & $503(30.7)$ & $358(29.6)$ & $145(33.8)$ & 0.10 \\
\hline Coronary heart disease $(\%)$ & $314(19.2)$ & $227(18.8)$ & $87(20.3)$ & 0.42 \\
\hline Diuretics (\%) & $971(59.3)$ & $690(57.1)$ & $281(65.5)$ & 0.002 \\
\hline ACE inhibitors (\%) & $540(33.0)$ & $401(33.2)$ & $139(32.4)$ & 0.76 \\
\hline $\operatorname{ARBs}(\%)$ & $640(39.1)$ & $480(39.7)$ & $160(37.3)$ & 0.49 \\
\hline Statins (\%) & $895(54.7)$ & $683(56.5)$ & $212(49.4)$ & 0.01 \\
\hline Antiplatelet drugs (\%) & $172(10.5)$ & $133(11.0)$ & $39(9.1)$ & 0.27 \\
\hline CHADS2 & $2.2 \pm 1.2$ & $2.1 \pm 1.2$ & $2.7 \pm 1.1$ & $<0.001$ \\
\hline CHA2DSVasc2 & $3.7 \pm 1.6$ & $3.5 \pm 1.6$ & $4.5 \pm 1.3$ & $<0.001$ \\
\hline HASBLED & $2.0 \pm 1.0$ & $1.9 \pm 1.7$ & $2.4 \pm 0.9$ & $<0.001$ \\
\hline Previous stroke (\%) & $264(16.1)$ & $197(16.3)$ & $67(15.6)$ & 0.97 \\
\hline Creatinine & $1.1 \pm 0.6$ & $1.0 \pm 0.5$ & $1.2 \pm 0.7$ & $<0.001$ \\
\hline GFR & $65.5 \pm 22.9$ & $69.5 \pm 23.7$ & $54.3 \pm 16.1$ & $<0.001$ \\
\hline Electrical cardioversion $(\%)$ & $282(17.2)$ & $256(21.2)$ & $26(6.1)$ & $<0.001$ \\
\hline Pharmacological cardioversion (\%) & $370(22.6)$ & $316(26.2)$ & $54(12.6)$ & $<0.001$ \\
\hline Pulmonary vein ablation (\%) & $64(3.9)$ & $60(5.0)$ & $4(0.9)$ & $<0.001$ \\
\hline Rhythm control (\%) & $621(37.9)$ & $515(42.6)$ & $106(24.7)$ & $<0.001$ \\
\hline Paroxysmal atrial fibrillation (\%) & $460(28.1)$ & $358(29.6)$ & $102(23.8)$ & $<0.001$ \\
\hline
\end{tabular}

COPD: chronic obstructive pulmonary disease. ACE: angiotensin converting enzyme. ARB: angiotensin receptor blocker. CHADS2: Congestive heart failure, Hypertension, Age > 74, Diabetes, Stroke/Transient Ischemic Attack. CHA $_{2}$ DS $_{2}$-VASc: Cardiac failure, Hypertension, Age > 74, Diabetes, Stroke, Vascular disease, Age 65-74 years, and Sex category. HAS-BLED:

Hypertension, Abnormal renal/liver function, Stroke, Bleeding history or predisposition, Labile international normalized ratio, Elderly (> 64 years) Drugs/alcohol concomitantly. GFR: Glomerular filtration rate. Q: Quartile. 


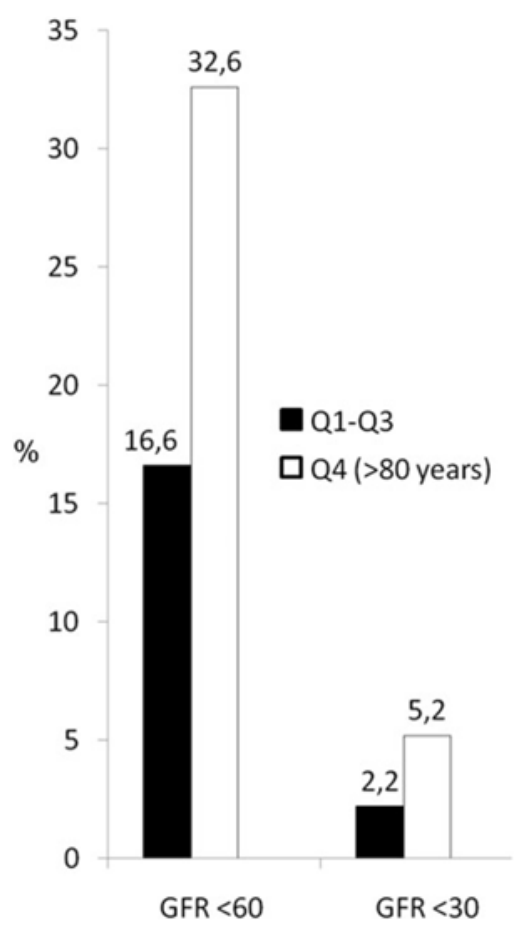

Fig. 1. Glomerular filtration rate (GFR) in $\mathrm{ml} / \mathrm{min}$ according with age quartile (Q).

Table 2. International normalized ratio (INR). Values in the 6 months prior to enrollment.

\begin{tabular}{lccccc}
\hline $\begin{array}{c}\text { Q1: 37-67 years } \\
\mathrm{N}=390\end{array}$ & $\begin{array}{c}\mathrm{Q} 2: 68-74 \text { years } \\
\mathrm{N}=371\end{array}$ & $\begin{array}{c}\text { Q3: 75-80 years } \\
\mathrm{N}=447\end{array}$ & $\begin{array}{c}\text { Q4: 81-99 years } \\
\mathrm{N}=429\end{array}$ & $\mathrm{p}$ \\
\hline & & & & \\
Month 1 & $2.5 \pm 0.6$ & $2.5 \pm 0.6$ & $2.5 \pm 0.7$ & $2.5 \pm 0.7$ & 0.477 \\
Month 2 & $2.5 \pm 0.8$ & $2.5 \pm 0.6$ & $2.4 \pm 0.7$ & $2.5 \pm 0.8$ & 0.684 \\
Month 3 & $2.5 \pm 0.82$ & $2.5 \pm 0.7$ & $2.5 \pm 0.7$ & $2.4 \pm 0.7$ & 0.42 \\
Month 4 & $2.5 \pm 0.8$ & $2.5 \pm 0.7$ & $2.5 \pm 0.7$ & $2.5 \pm 0.7$ & 0.729 \\
Month 5 & $2.5 \pm 0.8$ & $2.4 \pm 0.6$ & $2.5 \pm 0.8$ & $2.5 \pm 0.8$ & 0.872 \\
Month 6 & $2.5 \pm 0.7$ & $2.5 \pm 0.7$ & $2.5 \pm 0.8$ & $2.5 \pm 0.7$ & 0.75 \\
TTR & $61.9 \pm 24.6$ & $60.5 \pm 24.6$ & $62.6 \pm 24.5$ & $59.9 \pm 26.1$ & 0.511 \\
& & & & & \\
\hline
\end{tabular}

Q: quartile. TTR: time in the therapeutic range, calculated by the Rosendaal method.

\section{Discussion}

Octogenarians with nonvalvular AF have high risk of stroke (mean $\mathrm{CHA}_{2} \mathrm{DSVasc}_{2} 4.5$ ) and bleeding (mean HASBLEED 2.4) and frequent renal disease. In our registry VKAs anticoagulation quality was not associated with age. This is relevant as over $5 \%$ of octogenarians have severe renal disease where DOACs are not recommended [13]. Our results confirm that the use of VKAs in octogenarians is feasible in routine clinical practice. This is an important finding as the prevalence of AF increases with age [1] and [14]. Costa et al. [10] also found that elderly patients achieved a good quality of VKAs anticoagulation despite having a higher levels of comorbidities and polypharmacy. In the Swedish national quality registry for atrial fibrillation and anticoagulation (AuricuLA) [11] a correlation between age and major bleeding was found, but no correlation was seen between age and thrombo-embolic events. In this registry, age was associated with the need of a lower warfarin dose but elderly patients manage their warfarin therapy as well or even better than younger patients. On the other hand, Okumura et al. 
found the opposite [8], with a poorer TTR in the elderly, presumably related to physicians anxiety of major bleeding. A French national cross-sectional study [9] performed in octogenarians found that lowquality control of INR was mainly associated with comorbidities and the Veterans AffaiRs Study to Improve Anticoagulation (VARIA) [15] found an association in elderly patients between the number of concomitant medications and low-quality control of INR. Finally, Lefebvre et al. [16] have recently reported that the number of octogenarians with AF that receive anticoagulation is increasing and that $70 \%$ of them already anticoagulation therapy, with rates of anticoagulation clearly diminished among patients who are severely frail with advanced disability. Taken together these data suggest that more than age itself the presence of numerous comorbid conditions and polypharmacy may be the key issues and probably require greater attention by clinicians.

For more than 60 years, VKAs have been the only available oral anticoagulants for the prevention of stroke and systemic embolism in AF. Several new molecules, with a favorable pharmacokinetic profile and avoiding routine monitoring, have been recently developed, opening a new era in anticoagulation. However, DOACs are contraindicated in patients with severe renal disease [13], raise cost-effectiveness issues, and are not approved in patients with valvular AF [4] and [13]. Due to these reasons, VKAs are still largely used worldwide [11] and [17] and this will probably be true for the near future.

Our results are representative of Spain, but previous reports have shown that in Spain INR control is equal or superior to that in other Western countries such as Italy, France, the United States, or Canada [18] and [19]. Another peculiarity of our study is that in Spain the predominant VKA is acenocoumarol, as opposed to most Western countries, where warfarin is mainly used. Finally, by design, this study analyses drug treatment at the time of the enrollment visit, and does not include drug history or changes. On the other hand the FANTASIIA registry provides data of a large real-life population treated with VKAs with over a quarter $>80$ years.

\section{Conclusion}

In this large, nationwide survey, octogenarians with nonvalvular AF had high risk of stroke and bleeding and frequent renal disease. VKAs anticoagulation quality was similar in octogenarians and in younger patients.

\section{Conflict of interest}

None to declare.

\section{Funding}

The FANTASIIA Registry received an unrestricted grant from Pfizer/Bristol-Myers-Squibb (SEC2014001). This work was partially supported by the Red de Investigación Cardiovascular (RiC), Instituto de Salud Carlos III, Spanish Ministry of Health (Red RIC, RD120042/0001).

\section{Appendix A.}

Almendro, Manuel; Alonso-Pulpón, Luis (coordinator); Álvarez, Jorge; Anguera, Ignasi; Anguita, Manuel (coordinator); Arnulfo, Jorge; Bardají, Alfredo (coordinator); Barón, Gonzalo (coordinator); Bayés-Genís, Antonio (coordinator); Bellera, Neus; Bertomeu G., Vicente; Bonilla, Juan Luis; Brossa, Vicens; Buendía, Francisco; Camacho, José; Cano, Teresa; Casanova, Miguel Ángel; Casas, Josep; Castillo, Juan Carlos; Cobo, Marta $\mathrm{M}^{\mathrm{a}}$; Coca, Inmaculada; Colomer, Ingrid; Comín, Josep (coordinator); Cornide, Luis, Cosín, Juan (coordinator); Crespín, Manuel; Chinchurreta, Pedro; Chivite, David; Datino, Tomás; De Castro, Ramón; Delgado, José Gonzalo; Delgado, Mónica; Domingo, Mar; Elviro, Paloma; Escobar, Carlos; Esteban, Esther; Esteban, Fátima (coordinator); Fernandez, Antonio; Fernández, Andrés; Galve, Enrique (coordinator); Gámez, José María (coordinator); Gámez, Antonio Luis; García, Daniel (coordinator), García, Ana María; García, María Laura; García, Lorena; García, Miguel; García-Pavía, Pablo; García, Francisco José; Gil, Milagros; Giménez, Diego (coordinator); Gómez, Juan José (coordinator); Gómez, Silvia; González, Carlos (coordinator); Gonzálvez, Manuel; Hernández, Jesús Manuel; Hidalgo, Rafael ; (coordinator); Jiménez, Cristina; Jiménez, Javier (coordinator); Lambert, José Luis (coordinator); Lado, Manuel; Leal, Mariano; Lillo, Antonio; López, Laura; Madrigal, José Antonio; Manito, Nicolás (coordinator); Manzano, Sergio; Marco, Dolores; Marín-Ortuño, Francisco (coordinator); Martínez-Sellés, Manuel (coordinator); Mateos, Marta; Mayo, Rodrigo; Mazón, Pilar (coordinator); Medina, José Alejandro; Mesa, Javier; Mirabet, Sonia; Mogollón, M ${ }^{\text {a }}$ Victoria; Moreno, José (coordinator); Murga, Nekane (coordinator); Núñez, Juana; Olmos, Carmen; Otaegui, Imanol; Pascual, Jaume Francisco; Paya, Rafael; Pérez, Alejandro; Pérez, Jordi; Pérez, José Carlos; Pérez, José ; Pérez, 
Raquel; Piulats, Neus; Porras, Yolanda; Pose, Antonio; Quesada, Mª Angustias; Quirós, Raúl; Recalde, Esther, Ridocci, Francisco (coordinator); Ripoll, Tomás; Rodríguez, Marcos (coordinator); Roig, Eulalia (coordinator); Roldán, Inmaculada (coordinator); Romo, Elías; Rubio, José Manuel (coordinator); Ruiz, Martín; Rus, Carmen; Salas, Daniel; Sánchez, Pepa; Sarrias, Axel.; Serrano, Isabel; Sosa, César; Suarez, Manuel; Torres, Francisco (coordinator); Torres, Joan. Varela, Alfonso; Vázquez, Eduardo (coordinator); Vidán, María Teresa; Vilacosta, Isidre (coordinator); Villanueva, Elena; Villuendas, Roger; Vivas, David.

\section{References}

[1]. T. Wilke, A. Groth, S. Mueller, M. Pfannkuche, F. Verheyen, R. Linder, U. Maywald, R. Bauersachs, G. Breithardt. Incidence and prevalence of atrial fibrillation: an analysis based on 8.3 million patients. Europace, 15 (2013), pp. 486-493.

[2]. P.A. Wolf, R.D. Abbott, W.B. Kannel. Atrial fibrillation as an independent risk factor for stroke: the Framingham study. Stroke, 22 (1991), pp. 983-988.

[3]. F. Dentali, N. Riva, M. Crowther, A.G. Turpie, G.Y. Lip, W. Ageno. Efficacy and safety of the novel oral anticoagulants in atrial fibrillation a systematic review and meta-analysis of the literature. Circulation, 126 (2012), pp. 2381-2391.

[4]. J. Camm, G. Lip, R. De Caterina, I. Savelieva, D. Atar, H. S.H, G. Hindricks, P. Kirchhof, Authors/Task Force Members. Focused update of the ESC guidelines for the management of atrial fibrillation. Eur. Heart J., 33 (2012), pp. 2719-2747 2012.

[5]. F.R. Rosendaal, S.C. Cannegieter, F.J. Van der Meer, E. Briët. A method to determine the optimal intensity of oral anticoagulant therapy. Thromb. Haemost., 69 (1993), pp. 236-239.

[6]. S.J. Connolly, J. Pogue, J. Eikelboom. Benefit of oral anticoagulant over antiplatelet therapy in atrial fibrillation depends on the quality of international normalized ratio control achieved by centers and countries as measured by time in therapeutic range. Circulation, 118 (2008), pp. 2029-2037.

[7]. M. Anguita Sánchez, V. Bertomeu Martínez, F.A. Cequier. Quality of vitamin K antagonist anticoagulation in Spain: prevalence of poor control and associated factors. Rev. Esp. Cardiol., 68 (2015), pp. 761-768.

[8]. K. Okumura, T. Komatsu, T. Yamashita, Y. Okuyama, M. Harada, Y. Konta, T. Hatayama, D. Horiuchi, E. Tsushima. Time in the therapeutic range during warfarin therapy in Japanese patients with non-valvular atrial fibrillation. - a multicenter study of its status and infuential factors. Circ. J., 75 (2011), pp. 2087-2094.

[9]. A. Rouaud, O. Hanon, A.-S. Boureau, G.G. Chapelet, L. de Decker. Comorbidities against quality control of VKA therapy in non-valvular atrial fibrillation: a French national cross-sectional study. PLoS One, 10 (2015), pp. 119-130.

[10]. G.L. Costa, D.C. Ferreira, R.A. Valacio, C. Vieira Moreira Mda. Quality of management of oral anticoagulation as assessed by time in therapeutic INR range in elderly and younger patients with low mean years of formal education: a prospective cohort study. Age Ageing, 40 (2011), pp. 375-381.

[11]. M. Wieloch, A. Själander, V. Frykman, M. Rosenqvist, N. Eriksson, P.J. Svensson. Anticoagulation control in Sweden: reports of time in therapeutic range, major bleeding, and thrombo-embolic complications from the national quality registry AuriculA. Eur. Heart J., 32 (2011), pp. 2282-2289.

[12]. I. Roldán Rabadán, M. Anguita Sánchez, F. Marín, M.A. Quesada, J. Camacho Siles, R. Peinado, V. Bertomeu, Á. Cequier Fillat, L. Badimón, J. Muñiz. FANTASIIA study researchers. Current antiarrhythmic therapy for nonvalvular atrial fibrillation in Spain. Data from the FANTASIIA registry. Rev. Esp. Cardiol., 69 (2016), pp. 54-60. [13]. H. Heidbuchel, P. Verhamme, M. Alings, M. Antz, W. Hacke, J. Oldgren, P. Sinnaeve, J. Camm A, P. Kirchho. EHRA practical guide on the use of new oral anticoagulants in patients with non-valvular atrial fibrillation: executive summary. Eur. Heart J., 10 (2013), pp. 1093-1103.

[14]. M. Martínez-Sellés, í.d.l.B. Garc, A.J. Cruz-Jentoft, M.T. Vidán, P. Gil, L. Cornide, M. Ramos Cortés, J.L. González Guerrero, S.M. Barros Cerviño, Ó. Díaz Castro, T. Pareja, E. Sánchez, D. Cimera, M. Vigara, J. Balaguer, M.V. Mogollón Jiménez, F. Veiga Fernández, C. González Juanatey, A. Testa Fernández, J. Mateos Del Noza, S. Vázquez, N. Urueña, J. López Diaz. Centenarians and their hearts: a prospective registry with comprehensive geriatric assessment, electrocardiogram, echocardiography, and follow-up. Am. Heart J., 169 (2015), pp. 798-805. [15]. A.J. Rose, E.M. Hylek, A. Ozonoff, A.S. Ash, J.I. Reisman, D. Berlowitz. Patient characteristics associated with oral anticoagulation control: results of the veterans AffaiRs study to improve anticoagulation (VARIA). J. Thromb. Haemost., 8 (2010), pp. 2182-2191.

[16]. M.C. Lefebvre, M. St-Onge, M. Glazer-Cavanagh, L. Bell, J.N. Kha Nguyen, P. Viet-Quoc Nguyen, C. Tannenbaum. The effect of bleeding risk and frailty status on anticoagulation patterns in octogenarians with atrial fibrillation: the FRAIL-AF study. Can. J. Cardiol., 32 (2016), pp. 169-176.

[17]. P.A. Howard, E.F. Ellerbeck, K.K. Engelman, M.I. Dunn. Warfarin for stroke prevention in octogenarians with atrial fibrillation. Am. J. Geriatr. Cardiol., 10 (2001), pp. 139-144.

[18]. V. Pengo, C. Pegoraro, U. Cucchini, S. Lliceto. Worldwide management of oral anticoagulation therapy: the ISAM study. J. Thromb. Thrombolysis, 211 (2006), pp. 73-77.

[19]. J. Ansell, J. Hollowell, V. Pengo, F. Martinez-Brotons, J. Caro, L. Drouet. Descriptive analysis of the process and quality of oral anticoagulation management in real-life practice in patients with chronic non-valvular atrial fibrillation: the international study of anticoagulation management (ISAM). J. Thromb. Thrombolysis, 23 (2007), pp. 83-91. 